\title{
Research on Tendency and Behavior of the New Generation Employees Turnover
}

\section{- Based on Talent Environment Intervention Perspective}

\author{
Ruifeng Yang \\ School of Business Administration, South China University of Technology, Guangzhou, China \\ Email: yrf19491001@163.com
}

How to cite this paper: Yang, R.F. (2016) Research on Tendency and Behavior of the New Generation Employees Turnover. Journal of Human Resource and Sustainability Studies, 4, 325-336.

http://dx.doi.org/10.4236/jhrss.2016.44031

Received: October 11, 2016

Accepted: December 26, 2016

Published: December 29, 2016

Copyright $\odot 2016$ by author and Scientific Research Publishing Inc. This work is licensed under the Creative Commons Attribution International License (CC BY 4.0).

http://creativecommons.org/licenses/by/4.0/

\begin{abstract}
In recent years, a large number of new generation employees entered the enterprise and gradually became the mainstay of enterprises, but the turnover rate is high and it brought heavy pressure and burdens to employers. Therefore, considerable importance has been attached to the research on the behavior of the new generation employees by the academic researchers and business managers. Unfortunately, so far, there is little theoretical research on the behavior of the new generation employees from the perspective of talent environment. This paper makes a theoretical review of the environmental factors that affect the turnover behavior of new generation employees and then designs an effective intervention mechanism to reduce the turnover rate of new generation employees and provides the reference for the enterprise managers to make policies of keeping employees.
\end{abstract}

\section{Keywords}

Talent Environment, The New Generation Employees, Mechanism for Turnover Intervention

\section{Introduction}

In recent years, Chinese leaders such as president $\mathrm{Xi}$ Jinping and Premier Li Keqiang have made a series of important speeches about the work of talents. Among them, the President Xi repeatedly emphasized the need to make good use of talents. He stressed that China should establish a much more flexible talent management mechanism in order to eliminate obstacles of the flow and the use of talent, to maximize support and help for scientific and technological personnel to innovate enterprises and strive to create a favorable environment for the growth of innovative talents. With the conti- 
nuous improvement of China's market economic system and the accelerating pace of economic globalization, competition among enterprises has become increasingly fierce and corporate human resources have become the core competitiveness and important factor in sustainable development of enterprises.

After entering the 21st century, the new generation gradually transferred from the campus into the workplace and become the main force of enterprise development and competition. "The new generation employee" is a new vocabulary of management academia. In enterprise it mainly refers to those who were born in the 1990s and their age are in accordance with the "labor law" provisions of the staff [1]. They are a generation of witnessing Chinese higher education transfer from elite education to mass education and also they are the most creative and productive talents in the future. But they have great differences in the growth environment, ways of thinking and behavior characteristics from the employees in the past. The new generation employees' loyalty to the organization is weak, and so the problem of the new generation employee turnover has become the difficult point and the focus of human resource management. Of course, it also brings a lot of troubles to the organization and management. As the saying goes, "good birds choose wood and habitat". Therefore, enterprises must be combined with talent environment to retain talent. Based on this paper, from the perspective of talent environment, it is very important to find out the law of regional talent flow and new generation employee turnover and then put forward effective methods, which can not only help reduce the turnover of the new generation employees, but also improve the efficiency of leadership and management.

\section{Theory Review}

\section{1) Employee turnover}

Since the birth of modern enterprise management system, employee turnover has been a hot research topic. There are two main types of employee turnover: one is the employee's voluntary resignation, that is, the circumstance of active abdication, and the other is that the employee is disqualified or severely violates the company's rules and regulations, so the enterprise proposes to terminate the labor relationship between the two parties (Dessler, 2010) [2]. Historical experience shows that most of the turnover of enterprise core staffs is the initiative to leave, and they are often the key elements of the survival and development of enterprises. The employee turnover in this paper is mainly aimed at the situation of voluntary turnover. Voluntary turnover refers to the process that employees choose to take the initiative to leave the enterprise according to the enterprise and their own situation. The subject of employee turnover has already developed some research bases in the United States, Japan, Britain and some other industrialized countries. Price (1977) put forward the first influential model of employee turnover [3], and then on the basis of previous studies, researchers put forward many different models from different sides to study the mechanism of voluntary turnover. There are three main turnover models in the history of turnover research, including Intermediary Chain Model (Mobley, 1979) [4], Psychological Reason Model (Steers and Mow- 
day, 1981) and the model of Price-Mueller (2000) [5].

Intermediary Chain Model (Mobley, 1979) focused on the employee turnover intention, and then set up a model of employee turnover selection. Mobley stressed that leaving is a process of choosing, that employees intend to resign from the organization depend on four factors: job satisfaction, expected return of new job, expected return of original job, non-work values and occasional factors. Steers and Mowday (1981) proposed the model which depends on the basis of the models of Price and Mobley, seek to identify key variables that affect employees turnover and examine their relationship in the turnover process, and then expressed them in a conceptual model and block diagram. The model states that the following variables determine the leave or stay of employees in the organization. Firstly, job expectations and values affect the subjective attitude of employees to work. Secondly, subjective attitudes affect the intention to leave or remain, and also need to consider the influence of a number of non-working factors such as spouse work and family time. Moreover, the intention of leaving the organization leads to the actual separation behavior (Liu Shuzhen \& Li Yougen, 2008). The Price-Mueller (2000) model is based on an overall theory of turnover. The core of this theory consists of a series of assumptions. The model points out that employee turnover is mainly determined by four variables such as environment variables, individual variables, structured variables and intermediate variables. In this model, the expected external environment condition of the employee is called "environment variables", and the expected working conditions of the employee are referred to "structured variables". Individual variables (including general training, participating decision-making, positive or negative emotions) and intermediate variables (including job satisfaction, organizational commitment and turnover intention) are the other two variables.

In terms of model of employee turnover, the researches of Chinese scholars are less than that of the western countries. Chinese scholars mostly focus on the review of foreign models, or imitate, optimize, revise and test the established models of foreign scholars. Ma Shujie and Chen Jingqiu (2003) divided the factors of staff turnover into social level (labor market and economic factors), organizational level (organizational factors and work factors) and individual level (demographic factors, psychological factors and family factors) [6]. Ma Jingui and Zhang Changyuan (2005) constructed the "offbeat" employee turnover model which named "push-pull model". He believes that the negative factors in the organization are the thrust of employee turnover, and social factors are the force of employees to stay in the enterprise [7]. Qian Shiru (2014) discussed the relationship between psychological contract and turnover intention by using empirical data [8]. Linghu Ke Rui (2013) argued that turnover behavior of the new generation migrant workers is mainly affected by environment variables, individual variables, structural variables and process variables. Wang Zhenyuan and Sun Shanshan (2014) pointed out that the external attribution of colleague turnover events and the strength of the relationship among colleagues have a positive effect on the negative emotions and turnover intention of employees, which have a negative impact on job satisfaction and organizational commitment. Therefore, the turnover of individual em- 
ployees could lead to "dominos", which enterprises must pay great attention to [9].

To summarize, first of all, domestic and foreign previous research on staff turnover still mainly focus on the individual and organizational factors. And thus less attention be paid to the macro factors of community, region and society, especially lacks the mechanism of interaction among individual employees, business organizations and social factors. Secondly, under different culture backgrounds, the employee's turnover thinking and behavior will be different. Therefore, the study on the departure behavior of Chinese employees needs to not only refer to the usefulness of foreign researches, but also to combine it with the actual situation in their own country.

\section{2) The turnover of the new generation employees}

In China, the new generation is more popularly known as the "post-80s and post-90s". According to the "labor law" adopted by China in 1994, in addition to the arts, sports and special processing units, the legal working age of working population is 16 years old. Thus, for now, the age of the new generation employees is between 16 and 36. According to the data from "Chinese statistical yearbook", the number of the new generation employees is about 248 million, which is huge and cannot be ignored ( $\mathrm{Fu}$ Hong, Duan Wanchun, 2013) [10].

Due to different historical backgrounds was born, the new generation workers have shown some new features compared with the older generation workers, including strong desire to learn, good sense of innovation, strong need for respect and self-actualization, high self-awareness, disregard workplace unspoken rules, loss of sense of responsibility, high turnover rate, and so on. In the face of complex social and economic environment, the new generation employees are better than the older staff at mastering knowledge, skills, accepting new things, and learning ability, but the new generation employees are often more anxious at the pursuit of faster self-realization and are more dissatisfied with the status quo. All this resulted into the turnover rate staying at a high level. According to a Chinese enterprises survey about employee turnover in 2007, the average turnover rate of the modern service industry, traditional manufacturing industry and high-tech industry is $20.4 \%$, most of them are new generation employees. The turnover rate of employees with less than 2 years of work experience is $28 \%$ [1]. In 2015, the public data center conducted a comprehensive survey for the turnover rate of 2014. The result showed that graduates are lack of career planning, and the turnover rate at the first year of work is as high as $35.4 \%$. And what is worse, the turnover rate of employees with less than 3 years of work experience remained above $30 \%$. It could be argued that frequent job-hopping has become the occupational characteristics of post-90 generation employees. In addition, survey data also shows that the rate of voluntary employee turnover is much higher than the passive one.

The high turnover rate easily brings heavy financial and human capital loss to the enterprise, and the research on employee turnover intention is the focus of experts and scholars in recent years. Saporta and Farjoun (2003) argued that there is less chance of separation when employees have had better promotion opportunities within the organization. Duan Xingmin and Wang Yazhou (2005) summed up the seven factors that af- 
fect the turnover of knowledge workers by factor analysis, the first one is the employee's self development [11]. Wu Xiaoyi (2007) held that the new generation of employees have different characteristics and needs from older employees. Therefore, human resources management must adapt to the needs of the new generation of employees, and make a positive and forward-looking response and decision-making, so as to better attract, motivate and retain the talents of the new generation. Luo Exiang (2012) pointed out that the key reasons for the employee turnover are the family, salary, benefits, career development opportunities and training, working conditions, and so on. He proposed to proceed from the recruitment process, to establish a sound training and development system, and improve the salary and welfare system. Through the further improvement of staff working and living conditions, to meet the real needs of employees, improve the communication mechanism and so on to solve the problem of employee turnover [12]. In addition, there are a lot of scholars believed that the differences in leadership style will have a greater impact on the new generation employees [8].

\section{3) Talent environment}

Marx holds that people create an environment, the same environment also creates the people. It can be seen that the growth and development of talents are closely related to the environment. This close relationship makes the talent environment a very important part in the study of talent management. Guan Peilan and Zhou Xinjun (2009) argued that talent environment refers to the organizational environment, social environment and natural environment for human's survival and development. It includes all kinds of external factors that influence the growth of talents [13].

Peng Jianfeng (2004) pointed out that the competition of talent attraction, in essence, is the competition of talent ecological environment, and then he put forward that a good talent environment should have a series of indicators [14]. Talent environment has many unique properties. Luo Hongtie (2007) pointed out that the talent environment has the characteristics of systematicness and complexity, dynamism and stability, correlation and independence, humanity and nature [15]. There are many ways to divide the talent environment. According to the scope of the environment, the talent environment can be divided into small environment and macro environment. According to the boundary of the environment, it can be divided into the internal and external environment of talent. According to the nature of the environment, it can be divided into natural environment and social environment. According to the close degree of environment and material condition, it can be divided into hard environment and soft environment, or physical environment and spiritual environment. According to Maslow's hierarchy of needs, it can be divided into basic environment, dominant environment and driven environment. According to the nature of the environment on the role of talent, it can be divided into favorableness, adversity and normal. According to different talent subject system, it can be divided into micro talent environment, middle talent environment, and macro environment, and so on [13] [15].

At present, there are many researches on urban talent environment at home and 
abroad, and at the same time there are many mature scales. However, the researches on the talent environment of enterprises are relatively few. Therefore, this paper comprehensively analyzes the internal and external factors that affect the turnover of employees. And then from the perspective of talent environmental intervention, to further study the turnover behavior of the new generation employees.

\section{Intervention Mechanism}

Talent environment has a great impact on turnover behavior, especially in the era of information, science, technology and mobile network. Li Wenyong (2004) suspected that the role of talent is always inseparable from the specific environment. Environmental attraction and exclusion mechanisms play an important role. Talent environment has multiple effects and functions on talent's decision about whether to leave or stay, such as the function of environmental contrast effect and decision making, the function of environmental guidance and value added, the function of conditional control and interactional effect, as well as global and local effects [16]. Hu Yang (2007) pointed out that the battle for talent developed from the initial policy of war, price war to the current environmental warfare [17]. Throughout the history of all time, when the environment is good, people will get together, and the enterprise will flourish. On the contrary, when the environment is bad, the talent will be discrete, the cause will decline. As the saying goes, "man struggles upwards, water flows downwards". For most of the employees, they hope that their own enterprise has a good talent environment in order to have a suitable living space and growth opportunities. As the deterioration of the environment will lead to soil and water loss, the deterioration of the enterprise talent environment will lead to the loss of talent. Job hopping, although it seems to be personal behavior, in fact, more often is the refraction of corporate behavior. Therefore, when the enterprise employee turnover, what managers need to do is not only to try to retain a person, but also to reflect on whether the deterioration of enterprise talent environment has happened. According to Levin's field theory, there is a field strength function relationship among individual performance, ability and environment. If a person works in a bad environment, it is difficult for him to develop his talents, and it is difficult to achieve good performance. In this case, individuals are often difficult to change the impact of the environment, and only choose to leave the environment and go to a suitable environment for themselves [18]. David (2015) drew the conclusion with the social synergy theory and founded that three factors such as society, organizations and individual are acting synergistically on the flow of talent [19].

In fact, for the change of enterprise talent environment, it needs to pass the employee's perception and identity, and then to generate the intention of leaving, it may eventually lead to separations. The antecedents of organizational identification include three factors, individual factors, organizational factors and external environmental factors. An organization may have a lot of responses and interventions to the talent environment. Executives often also think that these policies have been implemented, but only when employees perceive the importance of these measures for them, these poli- 
cies and measures will become meaningful (Amabile et al., 1996) [20]. That is to say, only by the staff perceived, can the talent environment intervention mechanism play a real role. Wright and Nishii (2006) proposed a link relation between employee turnover and the environment. This relationship includes the external social environment and the natural environment (the change is passive, but the organization can take the initiative to adapt), the internal environment of the organization (what can be controlled to the extent by organization) and perceived talent environment (perceived by the staff) [21]. Subsequently, they pointed out that the employee's turnover intention and behavior is the feedback of the perception of the talent environment and intervention measures. Identity or not can cause psychological changes, leading to changes in attitude and behavior. When employees perceive the current talent environment is not able to meet their individual goals and needs, they always tend to find and choose the better one to meet their needs, and thus generate turnover intention. Currently, in the context of the mobile Internet, the new generation employees have become more convenient, efficient, and low perceived cost for the perception of the talent environment. As a result, the information asymmetry between enterprise talent environment and employees' perception will become weaker and weaker. There is no doubt that this will bring great challenges and threats to the enterprise.

As for the relationship between organizational identity and turnover intention, a large number of literatures have shown that organizational identity has negative predictive effect on turnover intention, including direct effect and indirect effect. Abrams (1998) argues that organizational identity is significantly negatively correlated with turnover intention and has a direct impact [22]. The survey of Bamber and Iyer (2002) also shows that organizational identity will significantly reduce the tendency of employee turnover [23]. Xiong Mingliang (2008) pointed out that employees' organizational identification will make him stand by a common fate with the organization. As a result, employees are more likely to be more closely associated with the organization, thereby weaken turnover intentions [24]. Organizational identity has a moderating effect on the relationship between employee's job satisfaction and turnover intention. In other words, under the premise of the same degree of satisfaction, the turnover intention is low when employees have high organizational identification, and the turnover intention is high when employees have low organizational identification [25]. Edwards and Peccei (2010) constructed the structural equation model of organizational support, employee organizational identification, employee participation and turnover intention. The result showed that employee organizational identification has a negative predictive effect on turnover intention, and then has a direct and indirect impact on employee involvement and turnover intention through organizational identification and organizational support [26].

Combined with the above analysis, this paper proposes a multi-path combinational intervention mechanism of talent environment. 1) The talent environment mainly refers to the organization environment, social environment and natural environment for the survival and development of talent, and the talent environment has a great impact 
on turnover behavior. 2) The new generation employees have special characters., and they pay more attention to the needs of high-level self-realization. Career attitudes of these employees vary widely and change rapidly. Especially in the context of mobile internet, they can more quickly and fully grasp the external information, which has a significant impact on employees' perception, identity and turnover intention. 3) According to the theory of social synergy, the synergy of social, organizational and personal factors leads to the flow of talents. The synergy of the talent environment and the characteristics of the new generation have led to the flow of the new generation employees. 4) The change of the talent environment needs to be perceived by the employees, and then to generate the intention of leaving, ultimately resulting in turnover behavior. 5) A large number of previous literatures show that the organizational identity of employees has a negative predictive effect on turnover intention. Based on the perspective of talent environment, this paper tries to find a preventive mechanism to solve the problem of the high turnover rate of the new generation employees (as Figure 1).

\section{Conclusions and Implications}

Talent is the foundation of the enterprise development. Recently, with the disappearance of Chinese demographic dividend, an increasing number of enterprises begin to be trapped in recruiting and retaining talent. According to the data from multiple recruitment sites, the turnover rate of the new generation employees in China is more than $60 \%$. Among them, nearly $30 \%$ of the staff quit frequently in a year with more than 5 times. How to reduce the turnover rate of the new generation employees, and improve their organizational loyalty and work enthusiasm, has become an urgent matter at the moment.

The talent environment of an enterprise is the basis for the survival and continuous improvement of talents. It can be said that a good talent environment is conducive to attract talents and beneficial to promote the sustained and stable development of enterprises, and finally achieve the scale effect of talent agglomeration. Therefore, if the enterprise wants to cultivate and retain the core employees of the new generation, and improve the enterprise loyalty of talents, reduce their turnover rate as well, enterprises should create an environment for the growth of talents, to meet the needs of their own development. That is to create the talent environment that enhances employee loyalty.

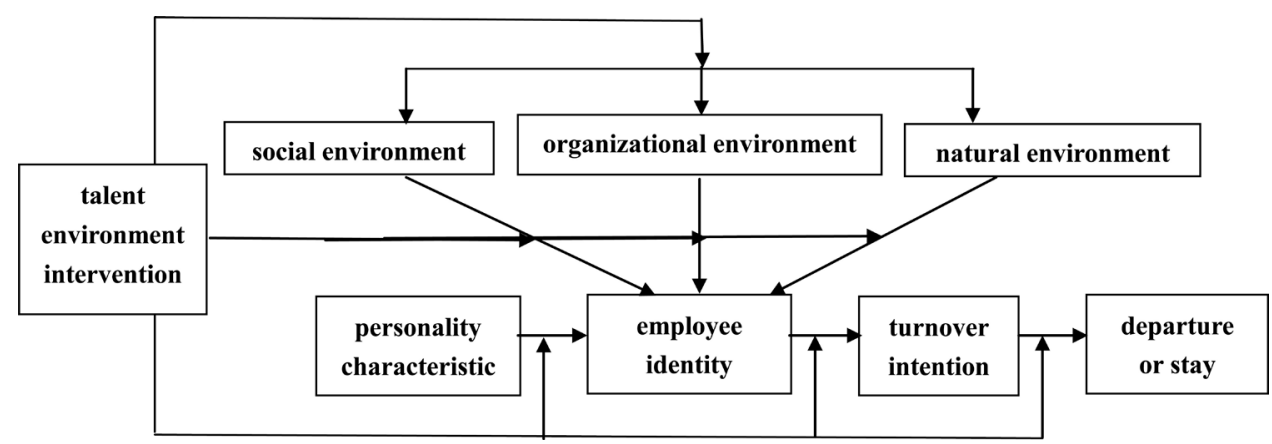

Figure 1. Intervention model of talent environment on the new generation employee turnover. 
From the perspective of the intervention mechanism of talent environment to employee turnover, under the background of the new generation employees with special characters, we can start from the point of view of talent environment, and then conduct multi-stage and all-round response and intervention to employees from their adapting to the environment to their implementing behavior of leaving. To be more specific, only organizational environmental factors can be controlled by enterprises, but companies still have the influence on the individual factors and external environmental factors by taking a variety of matching measures.

1) Establish a rapid response mechanism for environmental factors that are not controlled by the organization, including natural environment and social environment

For enterprises, in terms of uncontrollable environmental factors, Li Xiangmin and Ren Yushi (2007) emphasized that uncontrollable factors include alternative employment opportunities, market environment, economic conditions, scientific and technological environment, social environment, political environment, and so on. Because these environmental factors are mainly caused by external factors, it is difficult for enterprises to control them. Especially the development of the science and technology in the field of communication and internet provides more convenient access to the acquisition and utility of information [27]. From a macro point of view, regional government and society create a good environment for talent, and provide a good public resource and service (for example, library, internet, university, convenient transportation and living facilities), which will significantly improve the organizational commitment of talent, and thus reduce their turnover intention and behavior. Because the government and the social services have a great impact on cross-regional mobility of talent, enterprises in the region not only cannot passively allow employees to perceive the inferior position of enterprise talent environment, but also cannot passively respond to the reduction of employee organizational identification and the formation of turnover intention. Therefore, the enterprise should not only increase its business income, increase government revenue, increase employee income, and effectively fulfill their social responsibilities, but also actively promote the sharing of information resources within and outside the organization. At the same time, enterprises should grasp the latest developments of the external market environment, establish effective early warning systems and fast response mechanism for the changes of the external environment, and then make timely readjustment. In addition, enterprises can establish a harmonious relationship with the government, enterprises and institutions. In this way, the enterprise can get more involved in the decision-making process of government affairs, timely feedback related problems, and give advices and suggestions in order to create a good social environment and natural environment.

2) Strengthen intervene mechanism of the environmental factors controlled by the organization

In terms of controlled environment, it mainly includes job satisfaction, organizational commitment, organizational justice, organizational culture and so on. Many re- 
searchers show that employees are more likely to leave their jobs when they are dissatisfied, low commitment, lack of organizational justice, and in the case of weak organizational culture. Growth environment, sustainable surroundings, professional environment, personal environment, and recreational environment have a significant effect on the turnover intention and behavior. In fact, for the construction of the talent environment, it is not enough for enterprises to formulate relevant rules and regulations. The most important thing is to make employees perceive and identify the company's concern of their growth and the praise for their efforts. In order to achieve a better effect, companies should try to change the ways of employee's perception, evaluation and identification. For example, organizational culture in the organization's internal environment is a symbol of enterprise development ability and core competitiveness, which is beneficial for companies to create a strong centripetal force, appeal and cohesion. Through mutual selection, competition, organizational culture, professional career design and the improvement of incentive mechanism, the enterprises will gradually create an environment that will be beneficial to the growth of human resources. In addition, job satisfaction, organizational commitment, organizational justice, and colleague relationship are also closely related to employee turnover. Therefore, the enterprise should combine its own resources with the characteristics of the new generation employees, use innovative and flexible management methods to achieve interaction with them to increase the recognition of new employees to the company, reduce turnover intention and accumulate a wealth of human resources for the enterprise.

Mobley (1979) points out that turnover intention is the most predictive variable of turnover behavior. As long as we take a test for turnover intention, we can predict the possible factors which affect the future turnover. And then we can improve the intervention measures, so as to reduce the occurrence of turnover behavior [4]. According to the mechanism of talent environment intervention, the enterprise should not give up easily at this time because the enterprise can also take many intervention measures. Enterprises can identify and eliminate unfavorable environmental factors, so as to determine the key factors that influence the employee turnover behavior. If the enterprise takes effective measures, it can be successful to retain the core talents. In fact, even the employee had made a turnover decision, as long as it has not been put into action, the talent environment intervention can still play a role. In the end, enterprises can use the exit interview to implement the intervention measures. On the one hand, try to keep the employees you want. On the other hand, former employee can also be an important resource for the enterprise, such as supporter of the enterprise, customer or business partner. To make it more important, by founding out the reasons of the employee's leaving the company, to identify problems and provide a basis for solving the problem.

\section{3) Comprehensive and multi-stage interventions}

Combined with the intervention model, we can draw the conclusion that leaders and managers should take a variety of measures to deal with the problem of employee turnover, no matter it happened before and after turnover. Based on the internal and external environment of enterprise, on the one hand, the managers should pay atten- 
tion to the external environment, and be able to timely and accurately understand the needs of the new generation employees by the way of connecting social advanced enterprise and fashion trend. On this foundation, enterprises adopt targeted measures to retain key employees. On the other hand, enterprise managers should pay more attention to the internal environment of the enterprise, and use various methods of leadership and management measures to prevent and intervene the employee turnover that impenetrate the whole consider and decide process. Detailed measures can be: a) cultivate talents with the guidance of ability cultivation and career development; b) use scientific and reasonable performance evaluation and rewards and punishment system; c) customized incentive policy; d) excellent service for talent, including humanized management, flexible working hours, career planning and employee assistance program; e) create a distinctive corporate culture and a good working atmosphere; f) carry on the psychological management to the new generation employees.

\section{References}

[1] Lin, L.P. and Wang, H.B. (2012) AHP Analysis on the Turnover Reasons of the New Generation Employees. Jiangsu Commercial Forum, No. 3, 132-134.

[2] Dessler, G. (2010) Human Resource Management. Prentice Hall, Upper Saddle River, 612650 .

[3] Price, J.L. (1977) The Study of Turnover. Iowa State University Press, Ames, 45-60.

[4] Mobley, W., Griffeth, R., Hand, H. and Meglino, B. (1979) A Review and Concep-Tual Analysis of the Employee Turnover Process. Psychological Bulletin, 86, 517-532. http://dx.doi.org/10.1037/0033-2909.86.3.493

[5] Price, J.L. (2001) Reflections of Determinants of Voluntary Turnover. Journal of International Manpower, 22, 600-624. http://dx.doi.org/10.1108/EUM0000000006233

[6] Ma, S.J., Chen, J.Q. and Wang, L. (2003) Research on the Reason of Employee Turnover. Human Resource Development of China, No. 9, 18-20.

[7] Ma, J.G. and Zhang, C.Y. (2005) Cause Analysis and Countermeasures of Core Staff Turnover in Enterprises. Journal of Hunan Business College, No. 4, 42-44.

[8] Qian, S.R., Xu, Z.Q. and Wang, L.Q. (2015) Study on the Relationship between Psychological Contact Breach and Turnover Intention among the New Generation Employees. Modern Finance and Economics-Journal of Tianjin University of Finance and Economics, No. 2, 102-113.

[9] Wang, Z.Y., Sun, S.S. and Dai, R.L. (2014) Research of the Impact of Colleague Turnover on Stayer's Turnover Intention-A Mediated Moderating Model. Management Review, No. 4, 82-92.

[10] Fu, H. and Duan, W.C. (2013) The Characteristics and Motivations of the New Generation Employees in China-Reflections from the New Generation Hot Events. Social Scientist, No. 1, 88-91.

[11] Duan, X.M. and Wang, Y.Z. (2005) An Empirical Analysis on the Influencing Factors of Knowledge Workers' Turnover Intention. Human Resource Development of China, No. 5, 18-22.

[12] Luo, E-X., Wang, J.Y. and Wu, X.Y. (2012) Analysis on Causes and Solutions of Employee Turnover in SMEs: Based on the Study of S Company. Science-Technology and Manage- 
ment, No. 1, 116-119.

[13] Guan, P.L. and Zhou, X.J. (2009) Current Situation of Talent Environment in Wuhan and Its Countermeasures. To Promote the Rise of the Central China Expert Forum and the Fifth Hubei Science and Technology Forum in 2009, No. 1, 470-475.

[14] Peng, J.F. and Zhu, X.D. (2004) On the Scientific Connotation of Talent Powerful Country and Its System Promotion. Chinese Talents Magazine, No. 1, 39-42.

[15] Luo, H.T. (2007) Rediscussing the Principle System of Talents Studies. Journal of Southwest University (Humanities and Social Sciences Edition), No. 1, 107-110.

[16] Li, W. (2004) Study on the Optimization of Talent Environment in Shandong Province Based on the Analysis of Talent Flow. Master's Degree Thesis, Tianjin University, Tianjin.

[17] Hu, Y., Liu, G. and Li, L. (2007) Talent Environment Situation and Countermeasure StateOwned Enterprise under TBC. Journal of Hubei Correspondence University, 20, 16-19.

[18] Lewin, K. (1951) Field Theory in Social Science. Harper \& Brother Publishers, New York, 11-150.

[19] David, G. (2015) Talent Management: Progress and Prospects. Human Resource Management Review, 4, 233-235.

[20] Amabile, T.M., Conti, R., Coon, H., Lazenby, J. and Herron, M. (1996) Assessing the Work Environment for Creativity. Academy of Management Journal, 39, 1154-1184. http://dx.doi.org/10.2307/256995

[21] Wright, P.M. and Nishii, L.H. (2006) Strategic HRM and Organizational Behavior: Integrating Multiple Levels of Analysis. Cahrs Working Paper, Center for Advanced Human Resource Studies, Cornell University, Cornell, 43-66.

[22] Abrams, D., Ando, K. and Hinkle, S. (1998) Psychological Attachment to the Group: Cross-Cultural Difference in Organizational Identification and Subjective Norms as Predictors of Worker Turnover Intentions. Personality and Social Psychological Bulletin, 24, 1027-1039. http://dx.doi.org/10.1177/01461672982410001

[23] Bamber, E.M. and Iyer, V.M. (2002) Big 5 Auditors' Professional and Organizational Identification. Auditing. A Journal of Practice \& Theory, 21, 21-38. http://dx.doi.org/10.2308/aud.2002.21.2.21

[24] Xiong, M., Sun, J. and Gu, L. (2008) A Study on the Correlation between Job Satisfaction, Organizational Identification and Turnover Intention. Journal of Business Economics, 6, 34-40.

[25] Sun, J., Li, X. and Lin, C. (2016) Conceptual Evolution and Dimensional Measurement of Work Wellbeing. Human Resource Development of China, 38-47.

[26] Edwards, M.R. and Peccei, R. (2010) Perceived Organizational Support, Organizational Identification, and Employee Outcomes: Testing a Simultaneous Multifoci Model. Journal of Personnel Psychology, 9, 17-26. http://dx.doi.org/10.1027/1866-5888/a000007

[27] Li, X. and Ren, Y. (2007) Analyse on Employee's Turnover and Contributing Factor in Enterprise. Journal of Central University of Finance \& Economics, 65-70. 
Submit or recommend next manuscript to SCIRP and we will provide best service for you:

Accepting pre-submission inquiries through Email, Facebook, LinkedIn, Twitter, etc.

A wide selection of journals (inclusive of 9 subjects, more than 200 journals)

Providing 24-hour high-quality service

User-friendly online submission system

Fair and swift peer-review system

Efficient typesetting and proofreading procedure

Display of the result of downloads and visits, as well as the number of cited articles

Maximum dissemination of your research work

Submit your manuscript at: http://papersubmission.scirp.org/

Or contact jhrss@scirp.org 